\title{
Activation of the hypothalamic-pituitary adrenal axis in response to a verbal fluency task and associations with task performance
}

\author{
Linda Becker $\circledast^{*}$, Ursula Schade, Nicolas Rohleder $\odot$ \\ Department of Psychology, Friedrich-Alexander University Erlangen-Nürnberg, Erlangen, Germany \\ * linda.becker@fau.de
}

\section{Abstract}

Speech fluency can be impaired in stressful situations. In this study, it was investigated whether a verbal fluency task by itself, i.e. without the presence of any further stressors, induces responses of the hypothalamic-pituitary adrenal (HPA) axis and of the sympathetic nervous system (SNS). The sample consisted of $n=85$ participants (68.2\% female; $33.3 \pm$

\section{OPEN ACCESS}

Citation: Becker L, Schade U, Rohleder N (2020) Activation of the hypothalamic-pituitary adrenal axis in response to a verbal fluency task and associations with task performance. PLOS ONE 15 (4): e0227721. https://doi.org/10.1371/journal. pone. 0227721

Editor: Bruno Bonaz, Grenoble Faculty of Medicine and Hospital, FRANCE

Received: December 22, 2019

Accepted: April 1, 2020

Published: April 16, 2020

Copyright: ๑ 2020 Becker et al. This is an open access article distributed under the terms of the Creative Commons Attribution License, which permits unrestricted use, distribution, and reproduction in any medium, provided the original author and source are credited.

Data Availability Statement: All relevant data are within the manuscript and its Supporting Information files.

Funding: During this work, LB was postdoctoral research associate in the research project "Psychological and biological stress response patterns to digital stress" which is led by NR from the Institute of Psychology of the FriedrichAlexander University Erlangen-Nürnberg. The project is part of the Bavarian Research Association on Healthy Use of Digital Technologies and Media 15.2 years) who performed two consecutive verbal fluency tasks for two minutes each. The categories were either 'stress' or 'disease' and 'animals' or 'foods' which were presented in a randomized order. Three saliva samples were collected, prior to the task $\left(\mathrm{t}_{0}\right)$, immediately after $\left(t_{1}\right)$, and ten minutes after it $\left(t_{2}\right)$. Salivary $\alpha$-amylase and cortisol were assessed. Furthermore, blood pressure, heart rate, and ratings of actual stress perception, level of effort, and tiredness were measured. The verbal fluency task induced a HPA axis response with a maximum cortisol level at $\mathrm{t}_{2}$ which was independent of task performance. Furthermore, perceived stress and effort, as well as tiredness increased after the task. Moreover, tiredness immediately after the task was negatively correlated with task performance. No $\alpha$-amylase, blood pressure, or heart rate, and therefore SNS, responses were found. Implications for the integrated specificity model are discussed. We conclude that a verbal fluency task acts like an acute stressor that induces a cortisol and a perceived stress response without the need for further (e.g., social-evaluative) stress components. Therefore, it is a less time-consuming alternative to other stress tasks that can be used in field studies with little effort.

\section{Introduction}

Acute stress triggers a variety of physiological responses. The most prominent is the activation of the hypothalamus-pituitary adrenal (HPA) axis which leads to secretion of the stress hormone cortisol from the adrenal cortex [1,2]. Furthermore, the sympathetic nervous system (SNS) becomes activated in response to acute stressors which leads to the release of epinephrine and norepinephrine from the adrenal medulla, as well as to a variety of secondary reactions such as an increase in blood pressure and heart rate, and a decrease in heart rate variability [3-5]. 
(ForDigitHealth), funded by the Bavarian Ministry of Science and Arts. We acknowledge support by Deutsche Forschungsgemeinschaft and FriedrichAlexander-Universität Erlangen-Nürnberg (FAU) within the funding programme Open Access Publishing. The funders had no role in study design, data collection and analysis, decision to publish, or preparation of the manuscript.

Competing interests: The authors have declared that no competing interests exist.
Both stress systems can interact with the brain via direct and indirect pathways and can, therefore, alter brain chemistry which can consecutively alter cognitive functioning [6-8]. For example, retrieval from declarative long-term memory decreases after an acute stressor and this is associated with the HPA axis response [9-11]. Furthermore, working (or short-term) memory is affected in response to acute stressors which is associated with both the HPA axis and the SNS response [12-15]. Overviews about the associations between acute stress and cognitive functioning can be found in [16-19].

A cognitive function that has been less investigated so far, is verbal fluency (VF). At least two variants can be distinguished: first, semantic fluency (i.e., naming as many words as possible that belong to a specific category), and second phonemic fluency (i.e., naming as many words as possible that are beginning with a given letter). Verbal fluency in general requires a variety of cognitive processes such as long-term memory and working memory as well as executive functions [20,21]. Impairments in verbal fluency are often associated with frontal (phonemic and semantic fluency) or temporal (semantic fluency) brain lesions [22]. Therefore, verbal fluency tasks (VFT) are standard procedures in neuropsychological assessments.

It has been found previously that speech productivity can be impaired in acute stress situations. Buchanan, Laures-Gore, and Duff (2014; [23]) found that participants with high cortisol responses to the Trier Social Stress-Test (TSST; [24]) paused more during the stress task (and accordingly had a poorer VF performance) than participants with low cortisol responses. However, it cannot be deduced from these findings whether the poor VF performance was a result of the stress induction or whether the poor performance by itself led to an (additional) HPA axis response. Therefore, the aim of the present study was to investigate whether performing a VF task by itself, without any further stress induction, induces a stress response. If one was found, we were further interested in whether the stress response was associated with cognitive performance during the task. We hypothesized that a poor VF performance would be associated with a strong stress response. We decided to investigate semantic (and not phonemic) fluency and used a VFT in which as many words as possible that belong to a specific category should be named.

However, cognitive stressors are a special case of stressors because they do not threaten life but do indeed mobilize resources to face the task demands. The specific role of transmitted messenger molecules (e.g., stress hormones) is still unclear, though. Furthermore, it is discussed whether pure cognitive stressors trigger the same general stress response (i.e., an unspecific increase in SNS and HPA axis activity) or whether the stress response is specific and depends on the stressor characteristics, i.e. whether the stressor is, for example, cognitive, social-evaluative, or threatening $[25,26]$. Therefore, we differentiated between the activation of different stress systems: first, we investigated the perceived stress by the participants by means of rating scales, because it has been shown that stress perception can differ from physiological stress responses [27]. Second, reactivity of the HPA axis which was assessed using salivary cortisol measures. Third, the activation of the SNS which was measured by means of blood pressure, heart rate, and salivary alpha-amylase (sAA) assessments. The latter (sAA) has been shown to be a suitable non-invasive marker of SNS activation after acute stressors [28].

Furthermore, we aimed to investigate-if a response was found-whether this is associated with anthropometric and health factors (e.g., age, sex, body-mass index (BMI), depression, and use of oral contraceptives) that are typically related with HPA axis and SNS responses when other (usually social-evaluative) stress tasks are used (e.g., [29-35]). Since this was not the main research question of our study, we did not formulate specific hypotheses and investigated this exploratively instead. However, in order to achieve this goal, a heterogeneous sample was needed which was recruited from the general population. 


\section{Materials and methods}

\section{Participants}

From initially $n=101\left(67 / 101=66.3 \%\right.$ female; $34.9 \pm 15.2$ years; BMI $=23.7 \pm 4.0 \mathrm{~kg} / \mathrm{m}^{2} ; 81 /$ $101=80.2 \%$ non-smokers $)$ participants, ten $(10 / 101=9.9 \%)$ were excluded because they did not provide enough saliva for analysis, five $(5 / 101=5 \%)$ because German was not their mother tongue, and one $(1 / 101=1 \%)$ because his performance in the VFT was below three standard deviations from the sample's mean. The final sample consisted of $n=85$ healthy participants $\left(58 / 85=68.2 \%\right.$ female; $33.3 \pm 15.2$ years, min.: 18 , max.: 69 ; $\mathrm{BMI}=23.7 \pm 4.3 \mathrm{~kg} / \mathrm{m}^{2}$, $\min .: 18.2$ $\mathrm{kg} / \mathrm{m}^{2}$, max.: $41.5 \mathrm{~kg} / \mathrm{m}^{2} ; 71 / 85=83.5 \%$ non-smokers). Exclusion criteria were: usage of betablockers or glucocorticoid medication.

Most $(62 / 85=72.9 \%)$ of the participants reported that they are regularly engaged in exercise on $3 \pm 1.5$ days per week on average. According to the cut-off value by Stein and Luppa (2012; [36]), ten participants $(10 / 85=11.8 \%)$ were classified as depressive. Thirty-eight (38/ $85=44.7 \%)$ participants were classified as low and $47 / 85(55.3 \%)$ as high-chronically stressed. An overview of all relevant descriptive sample characteristics is provided in Tables 1 and 2.

An a-priori power analysis was performed, using $G^{*}$ Power (version 3.1.9.2). It indicated an optimal sample size of $n_{\text {optimal }}=82$. Power analysis was performed for an analysis of variance (ANOVA) for repeated measurements (rmANOVA) with an $\alpha$-level of $\alpha=.05$, a power of 1 $\beta=.95$, a medium effect size of $f=0.2$ for the main effect of the variable 'time', three groups (e.g., for the ratings), and three measurement time points $\left(t_{0}, t_{1}\right.$, and $\left.t_{2}\right)$. The dependent variables were either sAA, cortisol, mean arterial pressure (MAP), heart rate, or perceived stress levels. Therefore, we assume that the achieved sample size of $n=85$ is sufficient for the reported analyses.

All participants gave their written and informed consent. Data was anonymized directly after collection to protect participant's privacy. The study was approved by the data protection commission of the Friedrich-Alexander University Erlangen-Nürnberg (FAU). The study was conducted according to the principles expressed in the Declaration of Helsinki and was approved by the local ethics committee of the FAU (\#397_19 B).

\section{Materials}

Verbal fluency task. A semantic fluency task was used for assessing verbal fluency. The participants were given a category for which they should name as many terms as possible. Each participant was assigned two categories, one neutral and one emotional, and they were given two minutes time for each. The neutral category was either "animals" or "foods" as it is used in classical VF tasks (e.g., [37]). The emotional categories were either "stress" or "disease" which were developed by the authors themselves and which are not part of standard neuropsychological test batteries. By including this category, we intended to induce negative emotions

Table 1. Sample characteristics (mean, standard deviation, minimum, maximum) of the metric variables.

\begin{tabular}{l|c|c|c|c|c}
\hline Variable & N & Mean & Standard deviation & Minimum & Maximum \\
\hline Age & 85 & 33.3 & 15.2 & 18 & 18.2 \\
\hline BMI & 85 & 23.7 & 4.3 & 41,5 \\
\hline Sport days per week & 61 & 3.0 & 1.6 & 0 \\
\hline PSS scale & 85 & 15.4 & 6.8 & 2 & 7 \\
\hline CES-D scale & 80 & 14.2 & 9.0 & 2 & 36 \\
\hline
\end{tabular}

BMI: body-mass index; PSS: Perceived Stress Scale; CES-D: Center for Epidemiological Studies-Depression scale.

https://doi.org/10.1371/journal.pone.0227721.t001 
Table 2. Sample characteristics of the categorial variables.

\begin{tabular}{|c|c|c|c|}
\hline Variable & Label & Number & Percentage \\
\hline \multirow[t]{2}{*}{ Sex } & Female & 58 & 68.2 \\
\hline & Male & 27 & 31.8 \\
\hline \multirow[t]{4}{*}{ BMI classification } & Underweight & 2 & 2.4 \\
\hline & Normal weight & 61 & 71.8 \\
\hline & Pre-obese & 15 & 17.6 \\
\hline & Obese & 7 & 8,2 \\
\hline \multirow[t]{5}{*}{ Marital Status } & Single & 39 & 45.9 \\
\hline & Married & 23 & 27.1 \\
\hline & Partnership & 21 & 24.7 \\
\hline & Divorced & 1 & 1.2 \\
\hline & Widowed & 1 & 1.2 \\
\hline \multirow[t]{8}{*}{ Education } & Certificate of secondary education ('Hauptschulabschluss') & 4 & 4.7 \\
\hline & Secondary school level ('Mittlere Reife') & 11 & 12.9 \\
\hline & Vocational diploma ('Fachabitur') & 5 & 5.9 \\
\hline & General qualification for university entrance ('Abitur') & 35 & 41.2 \\
\hline & Bachelor's degree & 13 & 15.3 \\
\hline & Diploma or master's degree & 11 & 12.9 \\
\hline & $\mathrm{PhD}$ & 5 & 5.9 \\
\hline & Habilitation & 1 & 1.2 \\
\hline \multirow[t]{8}{*}{ Profession } & Unemployed & 2 & 2.4 \\
\hline & Trainee & 5 & 5.9 \\
\hline & Student & 31 & 36.5 \\
\hline & Employed & 36 & 42.4 \\
\hline & Self-employed & 1 & 1.2 \\
\hline & Official & 6 & 7.1 \\
\hline & Pension & 2 & 2.4 \\
\hline & Other & 2 & 2.4 \\
\hline \multirow[t]{3}{*}{ Smoking } & Yes, daily & 7 & 8.2 \\
\hline & Yes, sometimes & 7 & 8.2 \\
\hline & No & 71 & 83.5 \\
\hline \multirow[t]{2}{*}{ Alcohol consumption on study day } & Yes, but less than 2 beverages and not within the last 2 hours & 11 & 12.9 \\
\hline & No & 74 & 87.1 \\
\hline \multirow[t]{7}{*}{ General alcohol consumption } & No alcohol consumption & 10 & 11.8 \\
\hline & 1 day per week & 16 & 18.8 \\
\hline & 2 days per week & 11 & 12.9 \\
\hline & 3 days per week & 6 & 7.1 \\
\hline & 4 days per week & 1 & 1.2 \\
\hline & 5 and more days per week & 3 & 3.5 \\
\hline & Less than 1 day per week & 38 & 44.7 \\
\hline \multirow[t]{2}{*}{ Regular sports participation } & No & 23 & 27.1 \\
\hline & Yes & 62 & 72.9 \\
\hline \multirow[t]{6}{*}{ Sports classification } & Endurance sports & 36 & 42.4 \\
\hline & Strength training & 3 & 3.5 \\
\hline & Relaxation training & 3 & 3.5 \\
\hline & Endurance and strength training & 16 & 18.8 \\
\hline & Endurance and relaxation training & 4 & 4.7 \\
\hline & Endurance, strength, and relaxation training & 1 & 1.2 \\
\hline
\end{tabular}


Table 2. (Continued)

\begin{tabular}{|c|c|c|c|}
\hline Variable & Label & Number & Percentage \\
\hline \multirow[t]{2}{*}{ Use of oral contraceptives (women only) } & No & 47 & 81 \\
\hline & Yes & 11 & 19 \\
\hline \multirow[t]{2}{*}{ Perceived Stress Scale classification } & Low-chronically stressed & 38 & 44.7 \\
\hline & High-chronically stressed & 47 & 55.3 \\
\hline
\end{tabular}

https://doi.org/10.1371/journal.pone.0227721.t002

which potentially intensifies the stress reaction compared to a pure neutral VFT. However, it was not our aim to compare the physiological reactions between emotional and neutral VF tasks. The order of the categories was counterbalanced between the participants. Participants were voice recorded during the VFT, using a digital dictaphone (Olympus VN-541PC). For VFT evaluation, the number of correct terms $\left(\mathrm{VFT}_{\text {corr }, \mathrm{i}}\right)$, number of repetitions $\left(\mathrm{VFT}_{\text {rep }, \mathrm{i}}\right)$, and number of other errors $\left(\mathrm{VFT}_{\mathrm{oth}, \mathrm{i}}\right.$, e.g. wrong category) were determined and a performance score $\mathrm{VFT}_{\text {perf,i }}=\mathrm{VFT}_{\text {corr }, \mathrm{i}}-\left(\mathrm{VFT}_{\text {rep }, \mathrm{i}}+\mathrm{VFT}_{\text {oth, }, \mathrm{i}}\right)$ was calculated for each category $\mathrm{i}=\{1,2\}$. From these, a mean performance score $\mathrm{VFT}_{\text {perf }}=\left(\mathrm{VFT}_{\text {perf, } 1}+\mathrm{VFT}_{\text {perf, } 2}\right) / 2$ was calculated. Note: raw values instead of standard values were used for the VFT evaluation, because of the self-developed categories.

Rating scales. During each saliva sampling (at $t_{0}, t_{1}$, and $t_{2}$ ), perceived stress, level of effort, and tiredness were rated on 10-point Likert scales by the participants. The participants were asked "How stressed do you feel at this moment?", "How strong is your level of effort at this moment?", and "How tired do you feel at this moment?". The anchors were "not stressed at all" and "extremely stressed", "no effort" and "extreme effort", as well as "not tired" and "extremely tired".

Saliva sampling and analysis. Saliva samples were collected by means of salivettes (Sarstedt, Nümbrecht, Germany). Participants were instructed to keep the salivette in their mouth for at least one minute and to move it back and forth, but not to chew on it. Saliva samples were stored at $-30^{\circ} \mathrm{C}$ after collection for later analyses. Immediately before analysis, samples were centrifuged at $2000 \mathrm{~g}$ and $20^{\circ} \mathrm{C}$ for ten minutes. The same saliva samples were used for assessment of sAA and cortisol. From each saliva sample, $40 \mu \mathrm{l}(2 * 20 \mu \mathrm{l})$ were taken for cortisol and $20 \mu \mathrm{l}(2 * 10 \mu \mathrm{l})$ for sAA assessment. Salivary $\alpha$-amylase was measured with an inhouse enzyme kinetic assay using reagents from DiaSys Diagnostic Systems GmbH (Holzheim, Germany), as previously described [38,39]. In brief, saliva was diluted at 1:625 with ultrapure water and diluted saliva was incubated with substrate reagent ( $\alpha$-amylase CC FS; DiaSys Diagnostic Systems) at $37^{\circ} \mathrm{C}$ for three minutes before a first absorbance reading was taken at 405 $\mathrm{nm}$ with a Tecan Infinite $200 \mathrm{PRO}$ reader (Tecan, Crailsheim, Germany). A second reading was taken after five minutes incubation at $37^{\circ} \mathrm{C}$ and increase in absorbance was transformed to sAA concentration (U/ml), using a standard curve prepared using "Calibrator f.a.s." solution (Roche Diagnostics). Salivary cortisol concentrations were determined in duplicate using chemiluminescence immunoassay (CLIA, IBL, Hamburg, Germany). Intra- and inter-assay coefficients of variation were below $10 \%$ for both sAA and cortisol.

Blood pressure and heart rate. Systolic and diastolic blood pressure as well as heart rate were assessed by means of an upper arm blood-pressure monitor (boso medicus $\mathrm{X}$ ). Two participants $(2 / 85=2.4 \%)$ were excluded from blood pressure and heart rate analysis because of technical problems. Twenty-five participants $(25 / 85=29.4 \%)$ were classified as hypertonic because their blood pressure during the $t_{0}$ measurement was $\geq 140 / 90 \mathrm{mmHg}$. From these, only two $(2 / 85=8 \%)$ reported a hypertension diagnosis. The hypertonic participants were initially excluded from analysis of the blood pressure and heart rate time course, but further 
analyses were performed that confirmed that the same effects were found for hypertonic and non-hypertonic participants. Since blood pressure might be related to the other physiological variables as well and, therefore, with the sAA or cortisol response, we investigated whether the same sAA and cortisol time courses were found for hypertonic and non-hypertonic participants. However, no differences were found as well (see below). For analysis of the blood pressure time course in response to the VFT, MAP was calculated as MAP $=$ diastole +0.412 * (systole-diastole) [40].

Demographic variables, health status, and lifestyle factors. Self-developed questionnaires were used to assess demographic variables (age, sex, height, weight, marital status, educational level, occupation, monthly income), health status (physiological and psychological diseases, medication) and lifestyle factors (smoking, alcohol consumption, participation in regular sports). The medication variable was used to control whether the exclusion criteria (no usage of beta-blockers or glucocorticoids) were fulfilled which was the case for all included participants. Furthermore, a new variable 'use of oral contraceptives' was derived for the female participants. Body-mass index was calculated from height and weight according to BMI $=($ weight $[\mathrm{kg}]) /(\text { height }[\mathrm{m}])^{2}$ and was classified according to the norms provided by the World Health Organization as underweight $\left(<18.5 \mathrm{~kg} / \mathrm{m}^{2}\right)$, normal weight $\left(18.5-24.9 \mathrm{~kg} / \mathrm{m}^{2}\right)$, pre-obese $\left(25-29.9 \mathrm{~kg} / \mathrm{m}^{2}\right)$, and obese $\left(>29.9 \mathrm{~kg} / \mathrm{m}^{2}\right)$.

Depression. Depression was assessed by means of the German version of the long form of the depression scale from the Center for Epidemiological Studies (CES-D; [41,42]). A cut-off value of 22 was used for classification into depressed and non-depressed participants [36]. The range of values of this scale is between 0 and 60. Cronbach's $\alpha$ was $\alpha=.89$ in our study.

Perceived life stress/ chronic stress. The perceived level of life stress within the last four weeks was assessed by means of a validated German translation of the 10-item version of the Perceived Stress Scale (PSS; [43,44]). Cut-off values of 13 for women (all ages), 12 for men younger than 40 years, and 13 for men equal to or above 40 years were used to differentiate between low-chronically stressed and high-chronically stressed participants [44]. The range of values of the PSS is between 0 and 40. Cronbach's $\alpha$ was $\alpha=.88$ in our study. Note: although the PSS assesses perceived stress within the last month and not explicitly chronic stress, we refer to it as a measure of chronic stress in the following to avoid confusion with our acute perceived stress measurement.

Affect. As last part of the questionnaire battery and immediately before the last saliva sample, actual affect was assessed by means of a German version of the Positive and Negative Affect Schedule (PANAS; [45-47]). The PANAS contains 20 adjectives (10 positive and 10 negative) based on which the current affective state should be rated. Cronbach's $\alpha$ was $\alpha=.94$ for positive affect and $\alpha=.87$ for negative affect in our study.

\section{Procedure}

About half of the participants $(48 / 85=56.5 \%)$ came to our laboratory during a public event in the evening on a weekend between 6 p.m. and 1 a.m. where they were recruited and could immediately participate. The other sessions took part on weekdays between 9 a.m. and 6 p.m. For the morning sessions, the participants were instructed to have gotten-up at least two hours before the start of the experiment. Participants refrained from drinking (except water) and eating within at least one hour prior to the experiment.

Participants were seated in a comfortable chair in a quiet room. After they were informed about the experimental procedure, they gave their written consent for participation, and the first saliva sample $\left(\mathrm{s}_{0}\right)$ was collected, and blood pressure and heart rate were measured for the first time. The VFT was then introduced to the participants and started immediately. The 


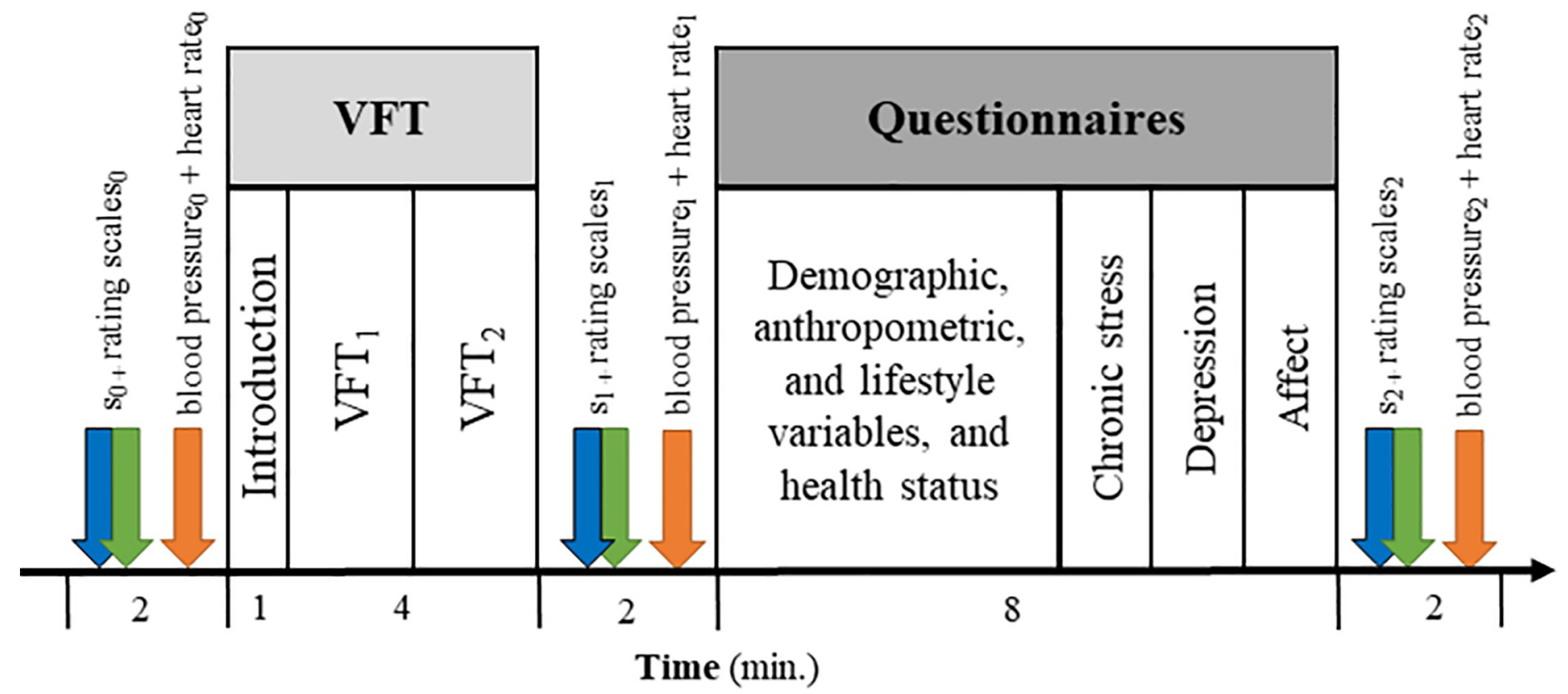

Fig 1. Time course of the experiment. Three saliva samples $s_{0}, s_{1}$, and $s_{2}$ were collected at the time points $t_{0}$, $t_{1}$, and $t_{2}$. The verbal fluency task (VFT) was performed between the first and the second saliva sample and consisted of two parts $\left(\mathrm{VFT}_{1}\right.$ and $\left.\mathrm{VFT}_{2}\right)$. Furthermore, blood pressure was measured after each saliva sample.

https://doi.org/10.1371/journal.pone.0227721.g001

experimenters stayed in the room during the task. After this, the second saliva sample $\left(\mathrm{s}_{1}\right)$ was collected and both blood pressure and heart rate were measured. To fill the gap between the second and third saliva collection, participants filled-out questionnaires, assessing their demographic variables, health status, depression, chronic life stress-perception, actual affect, and lifestyle factors. Ten minutes after $s_{1}$, the last saliva sample $\left(s_{2}\right)$ was taken and blood pressure and heart rate were measured again. If necessary, participants were given more time to complete the questionnaires after $\mathrm{s}_{2}$. However, not everyone was willing to stay longer, so some questionnaire data is missing. Finally, weight and height were measured. During collection of the saliva samples, participants rated their actual perceived stress level, level of effort, and tiredness. The time course of the whole experiment is shown in Fig 1. The whole session lasted between 20 and 30 minutes, depending on the time needed for informing the participants and for filling-out the questionnaires.

\section{Statistical data analysis}

For statistical analyses, IBM SPSS Statistics (version 26) was used. Normality of distribution was tested by means of the Kolmogorov-Smirnov test. Because of positive skewness and violation of normality, sAA levels were transformed by means of the square root transformation and cortisol levels by means of the natural logarithm prior to further statistical analysis. The data set that was used for statistical analysis and the corresponding codebook can be found in the S1 and S2 Files.

Main analyses. To test our main hypotheses (that the VFT leads to reactions of the SNS and the HPA axis as well as to changes in the stress, effort, and tiredness ratings), rmANOVAs with the within-subject factor 'time' $\left(t_{0}, t_{1}\right.$, and $\left.t_{2}\right)$ were calculated, separately for perceived stress ratings, sAA, and cortisol levels as well as for MAP and heart rate. For perceived stress ratings, the within-subject factor 'state' with the levels 'stress', 'effort', and 'tiredness' was included. To correct for multiple comparisons and because six separate rmANOVAs were 
calculated, an adjusted $\alpha$-level of $\alpha_{\text {adjusted }}=\alpha / 6=0.05 / 6=0.008$ was calculated according to the Bonferroni correction procedure [48]. Partial eta-squares $\left(\eta_{\mathrm{p}}{ }^{2}\right)$ were considered as effect sizes. Sphericity was tested by means of the Mauchly test [49]. If necessary, degrees of freedom were corrected by means of the Greenhouse-Geisser procedure [50]. For post-hoc analysis, $t$ tests for dependent samples were calculated and Cohen's $d$ was considered as measure for effect sizes: $d=\left(\mathrm{M}_{1}-\mathrm{M}_{2}\right) / \sigma$ with the means $\mathrm{M}_{1}$ and $\mathrm{M}_{2}$ and the standard deviation $\sigma$. For these dependent $t$-tests, Cohen's $d$ was corrected according to the method that was proposed by Morris (2008, [51]) after which the standard deviation $\sigma$ is corrected as $\sigma_{\text {corr }}=\sigma^{*}\left[2^{*}(1-\mathrm{r})\right]^{1 / 2}$, including the correlation $r$ between variable 1 and 2 .

Further and exploratory analyses. To investigate whether different orders in the VFT and the different categories that were used were associated with VF performance, a one-factorial ANOVA with the between-subjects factor 'order' (stress/animals, stress/foods, disease/animals, disease/foods, animals/stress, animals/disease, foods/stress, and foods/disease) was calculated. Furthermore, dependent $t$-tests were used to investigate whether performance differed between the neutral and emotional VFT as well as between the stress and disease and the animals and foods category.

For the exploratory analyses (i.e., to investigate whether the stress response or VFT performance, or the baseline levels were associated with age, sex, BMI, depression, chronic stress, or time of day), Pearson correlations were calculated. A Bonferroni-adjusted $\alpha$-level of $\alpha_{\text {adjusted }}=$ $0.05 / 24=0.002$ was used because 24 correlations were calculated (for sAA, cortisol, stress, effort, tiredness, MAP and heart rate at three time points, positive and negative affect, and $\left.\mathrm{VFT}_{\text {perf }}\right)$. Furthermore, it was examined whether differences in group means between depressed and non-depressed, high- and low-chronically stressed, and between hypertonic and non-hypertonic participants could be found. For this, independent $t$-tests with the same adjusted $\alpha$-level of $\alpha_{\text {adjusted }}=0.002$ were calculated. Furthermore, it was investigated whether the physiological variables or VF performance differed between women that use oral contraceptives and women that do not by means of further independent $t$-tests. For these, an adjusted $\alpha$-level of $\alpha_{\text {adjusted }}=0.05 / 13=0.004$ was used because 13 tests were performed (VFT performance and sAA, cortisol, MAP and heart rate at all three time points).

For further investigation of the associations between cortisol baseline levels and the cortisol time course, the variable 'time of day' was categorized into 'early' (before 12 p.m.), medium (12-18 p.m.), and late (after 18 p.m.). A further rmANOVA for cortisol was calculated with the within-subjects factor 'time' $\left(t_{0}, t_{1}\right.$, and $\left.t_{2}\right)$ and the between-subjects factor 'time of day category' ('early', 'medium', and 'late'). Note: Unfortunately, it was not possible to investigate whether educational level was associated with VF performance because of too small group sizes.

\section{Results}

\section{Verbal fluency performance}

The mean VFT performance was $V_{F T}$ perf $=26.9 \pm 7.3$ words (min.: 10.5, max: 48.5). Mean VFT performances for each category are summarized in Table 3. Mean VF performances did not differ between the different presentation orders and category combinations (stress/animals, stress/foods, disease/animals, disease/foods, animals/stress, animals/disease, foods/stress, and foods/disease; $\left.F_{(7)}=0.36, p=.925\right)$. Verbal fluency performance did not differ between the stress and disease category $\left(t_{(83)}=-1.88, p=.063, d=0.38\right)$ as well as between the animals and foods category $\left(t_{(83)}=-1.21, p=.230, d=0.26\right)$. However, performance in the emotional VFT was significantly lower than in the neutral VFT $\left(t_{(84)}=-12.1, p<.001, d=1.51\right)$. 
Table 3. Mean performances in the different verbal fluency tasks.

\begin{tabular}{l|c|c|c|c}
\hline Category & Mean & Minimum & Maximum & Standard deviation \\
\hline Stress & 18.1 & 2 & 47 & 8.6 \\
\hline Disease & 21.3 & 6 & 41 & 7.1 \\
\hline Animals & 32.7 & 11 & 68 & 10.9 \\
\hline Foods & 35.3 & 10 & 51 & 9.3 \\
\hline
\end{tabular}

https://doi.org/10.1371/journal.pone.0227721.t003

\section{Perceived stress ratings and affect}

For the rating scales, a main effect of time $\left(F_{(2,168)}=42.69, p<.001, \eta_{\mathrm{p}}{ }^{2}=.34\right)$, a main effect of state $\left(F_{(1.45,121.75)}=6.64, p=.005, \eta_{\mathrm{p}}{ }^{2}=.07\right)$ and an interaction time $\mathrm{x}$ state $\left(F_{(3.0,251.68)}=\right.$ $40.08, p<.001, \eta_{\mathrm{p}}{ }^{2}=.32$; Fig $2 \mathrm{~A}$ ) were found. Post-hoc rmANOVAs showed that all states significantly changed during the experiment, i.e. that a main effect of time was found (stress: $F_{(2}$, ${ }_{168)}=56.00, p<.001, \eta_{\mathrm{p}}{ }^{2}=.40$, effort: $F_{(2,168)}=7.17, p=.001, \eta_{\mathrm{p}}{ }^{2}=.08$, tiredness: $F_{(2,168)}=$ $\left.48.50, p<.001, \eta_{\mathrm{p}}{ }^{2}=.37\right)$. Post-hoc $t$-tests showed that perceived stress significantly increased between $\mathrm{t}_{0}$ and $\mathrm{t}_{1}\left(t_{(84)}=-8.61, p<.001, d=1.00\right)$ and decreased between $\mathrm{t}_{1}$ and $\mathrm{t}_{2}\left(t_{(84)}=9.80\right.$, $p<.001, d=1.01)$. Effort ratings significantly increased between $\mathrm{t}_{0}$ and $\mathrm{t}_{1}\left(t_{(84)}=4.30, p<\right.$ $.001, d=0.46)$. Tiredness significantly increased between $\mathrm{t}_{0}$ and $\mathrm{t}_{1}\left(t_{(84)}=-9.60, p<.001\right.$, $d=1.32)$ and decreased between $\mathrm{t}_{1}$ and $\left.\mathrm{t}_{2}\left(t_{(84}\right)=6.40, p<.001, d=0.82\right)$. Only tiredness at $\mathrm{t}_{1}$ was correlated with task performance $\left(r_{(84)}=-.33, p=.002\right.$; Fig $\left.2 \mathrm{~B}\right)$. None of the other ratings was associated with VFT performance after correction for multiple comparisons (all $p \geq .044$ ). The mean values of the ratings are provided in Table 4.

Immediately before $t_{2}$, the PANAS was filled-out by the participants. At this time point, positive affect was significantly higher than negative affect $\left(t_{(77)}=16.35, p<.001, d=1.5\right.$, $\left.\mathrm{M}_{\text {positive }}=3.03 \pm 0.71, \mathrm{M}_{\text {negative }}=1.38 \pm 0.41\right)$. After correction for multiple comparisons, a marginally significant negative correlation between negative affect and VFT performance was found $\left(r_{(76)}=-.27, p=.017\right)$. Neither positive nor negative affect was related with any of the other physiological or psychological variables at $\mathrm{t}_{2}($ all $p \geq .053)$.

\section{Alpha-amylase}

Salivary $\alpha$-amylase levels did not significantly differ between the three measurement-time points $\left(F_{(1.8,150.0)}=0.69, p=.487, \eta_{\mathrm{p}}^{2}=.008\right.$; Fig $\left.3 \mathrm{~A}\right)$. Salivary $\alpha$-amylase levels were not
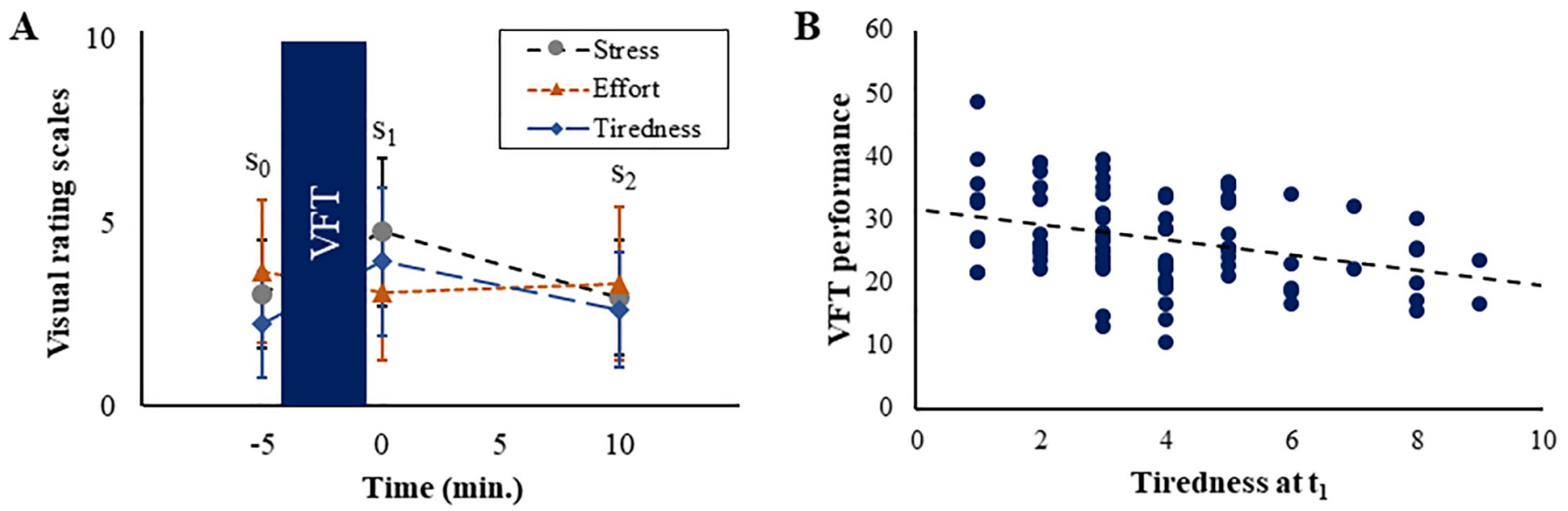

Fig 2. Ratings and significant association with task performance. (A) Time course of ratings for perceived stress, effort, and tiredness with respect to the verbal fluency task (VFT). Standard deviations are shown as error bars. (B) Association between VFT performance and tiredness at $\mathrm{t}_{1}$.

https://doi.org/10.1371/journal.pone.0227721.g002 
Table 4. Mean values and standard deviations of the perceived ratings and the scales of the Positive and Negative Affect Schedule (PANAS).

\begin{tabular}{|c|c|c|c|c|c|}
\hline & $\mathbf{N}$ & Mean & Standard deviation & Minimum & Maximum \\
\hline Stress $t_{0}$ & 85 & 3.1 & 1.8 & 1 & 8 \\
\hline Stress $t_{1}$ & 85 & 4.7 & 2.0 & 1 & 9 \\
\hline Stress $t_{2}$ & 85 & 3.0 & 1.7 & 1 & 8 \\
\hline Effort $t_{0}$ & 85 & 3.7 & 2.0 & 1 & 8 \\
\hline Effort $t_{1}$ & 85 & 3.1 & 1.8 & 1 & 8 \\
\hline Effort $t_{2}$ & 85 & 3.3 & 2.1 & 1 & 10 \\
\hline Tiredness $\mathrm{t}_{0}$ & 85 & 2.2 & 1.5 & 1 & 7 \\
\hline Tiredness $t_{1}$ & 85 & 3.9 & 2.0 & 1 & 9 \\
\hline Tiredness $t_{2}$ & 85 & 2.6 & 1.6 & 1 & 9 \\
\hline PANAS positive & 78 & 3.0 & 0.7 & 1.30 & 4.30 \\
\hline PANAS negative & 78 & 1.4 & 0.4 & 0.90 & 3.30 \\
\hline
\end{tabular}

associated with VFT performance (all $p \geq .293$ ). When only including the non-hypertonic participants into the analysis, no main effect of time was found $\left(F_{(1.8,101.9)}=3.07, p=.057, \eta_{\mathrm{p}}{ }^{2}=\right.$ $.05)$. No associations with VF performance were found as well (all $p \geq .278$ ). An overview of the mean sAA levels and of all other physiological variables at all three time points is provided in Table 5.

\section{Cortisol}

For cortisol, a main effect of the factor time was found $\left(F_{(2,168)}=19.29, p<.001, \eta_{\mathrm{p}}{ }^{2}=.19\right.$, Fig $3 B)$. Post-hoc analyses showed that cortisol levels significantly increased between $t_{0}$ and $t_{1}$ $\left(t_{(84)}=-3.58, p=.001, d=1.48\right)$ and increased further between $t_{1}$ and $t_{2}\left(t_{(84)}=-4.0, p<.001\right.$, $d=0.44$ ). However, cortisol levels were not associated with VFT performance (all $p \geq .370$ ).

\section{Blood pressure and heart rate}

When all participants were included into the analysis, a main effect of the factor time was found $\left(F_{(2,159.8)}=6.36, p=.002, \eta_{\mathrm{p}}{ }^{2}=.06\right.$, Fig $\left.4 \mathrm{~A}\right)$. Post-hoc $t$-tests showed an marginal significant decrease in heart rate between $\mathrm{t}_{0}$ and $\mathrm{t}_{1}\left(t_{(82)}=2.17, p=.033, d=0.23\right)$. Heart rate was
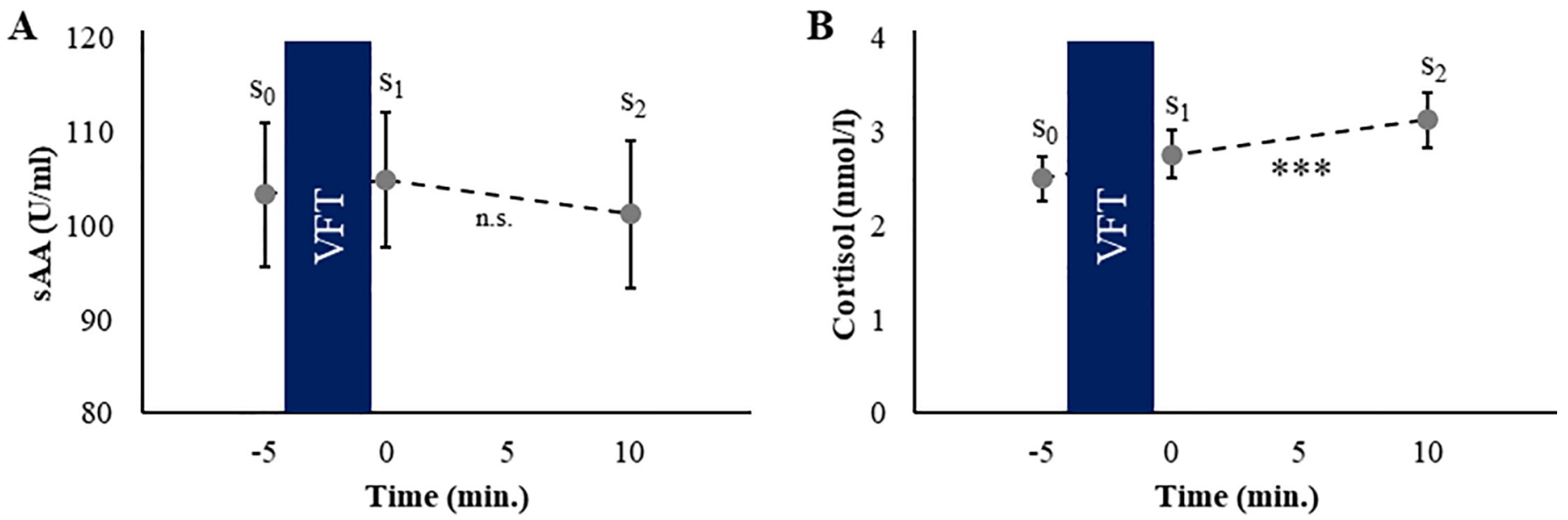

Fig 3. Alpha-amylase and cortisol responses. (A) Time course of salivary $\alpha$-amylase (sAA) with respect to the verbal fluency task (VFT). (B) Cortisol time course. Standard errors are shown as error bars.

https://doi.org/10.1371/journal.pone.0227721.g003 
Table 5. Mean values and standard deviations of the physiological variables.

\begin{tabular}{|c|c|c|c|c|c|}
\hline & $\mathbf{N}$ & Mean & Standard deviation & Minimum & Maximum \\
\hline Cortisol $\mathrm{t}_{0}(\mathrm{nmol} / \mathrm{l})$ & 85 & 2.5 & 2.2 & 0.3 & 10.7 \\
\hline Cortisol $\mathrm{t}_{1}(\mathrm{nmol} / \mathrm{l})$ & 85 & 2.8 & 2.4 & 0.5 & 12.8 \\
\hline Cortisol $\mathrm{t}_{2}(\mathrm{nmol} / \mathrm{l})$ & 85 & 3.1 & 2.7 & 0.5 & 13.8 \\
\hline $\mathrm{sAA} \mathrm{t}_{0}(\mathrm{U} / \mathrm{ml})$ & 85 & 103.3 & 71.0 & 3.9 & 331.2 \\
\hline $\mathrm{sAA} \mathrm{t}_{1}(\mathrm{U} / \mathrm{ml})$ & 85 & 104.9 & 66.3 & 5.3 & 302.8 \\
\hline $\mathrm{sAA} \mathrm{t}_{2}(\mathrm{U} / \mathrm{ml})$ & 85 & 101.2 & 72.5 & 1.9 & 306.3 \\
\hline Systole $\mathrm{t}_{0}(\mathrm{mmHg})$ & 84 & 132.1 & 18.1 & 82 & 192 \\
\hline Systole $\mathrm{t}_{1}(\mathrm{mmHg})$ & 83 & 130.1 & 16.6 & 102 & 178 \\
\hline Systole $\mathrm{t}_{2}(\mathrm{mmHg})$ & 83 & 127.6 & 15.5 & 104 & 179 \\
\hline Diastole $\mathrm{t}_{0}(\mathrm{mmHg})$ & 83 & 83.6 & 9.2 & 63 & 118 \\
\hline Diastole $\mathrm{t}_{1}(\mathrm{mmHg})$ & 83 & 82.7 & 9.7 & 61 & 108 \\
\hline Diastole $\mathrm{t}_{2}(\mathrm{mmHg})$ & 83 & 82.0 & 10.4 & 50 & 104 \\
\hline $\mathrm{MAP}_{0}(\mathrm{mmHg})$ & 83 & 103.4 & 11.7 & 70.8 & 136.7 \\
\hline $\mathrm{MAP}_{1}(\mathrm{mmHg})$ & 83 & 102.2 & 11.2 & 80.2 & 129.4 \\
\hline $\mathrm{MAP}_{2}(\mathrm{mmHg})$ & 83 & 100.8 & 11.6 & 73.9 & 128.4 \\
\hline Heart rate $t_{0}(\mathrm{bpm})$ & 83 & 75.1 & 12.3 & 51 & 111 \\
\hline$\underline{\text { Heart rate } \mathrm{t}_{1}(\mathrm{bpm})}$ & 83 & 73.4 & 11.7 & 47 & 105 \\
\hline Heart rate $t_{2}(\mathrm{bpm})$ & 83 & 72.5 & 10.6 & 46 & 99 \\
\hline
\end{tabular}

sAA: salivary $\alpha$-amylase; MAP: mean arterial pressure; bpm: beats per minute.

https://doi.org/10.1371/journal.pone.0227721.t005

not associated with VFT performance (all $p>.288$ ). When only the non-hypertonic participants were included into the analyses, no effects were found (all $p \geq .069$ ).

When all participants were included into the analysis, no main effect of the factor time was found for MAP $(p=.04)$. No associations between MAP and VFT performance were found, neither for the whole sample nor for the non-hypertonic participants (all $p \geq .103$ ).

\section{Exploratory analysis}

To investigate whether anthropometric and health factors (e.g., age, sex, BMI, chronic stress, depression, and use of oral contraceptives) which are typically related with HPA axis and SNS
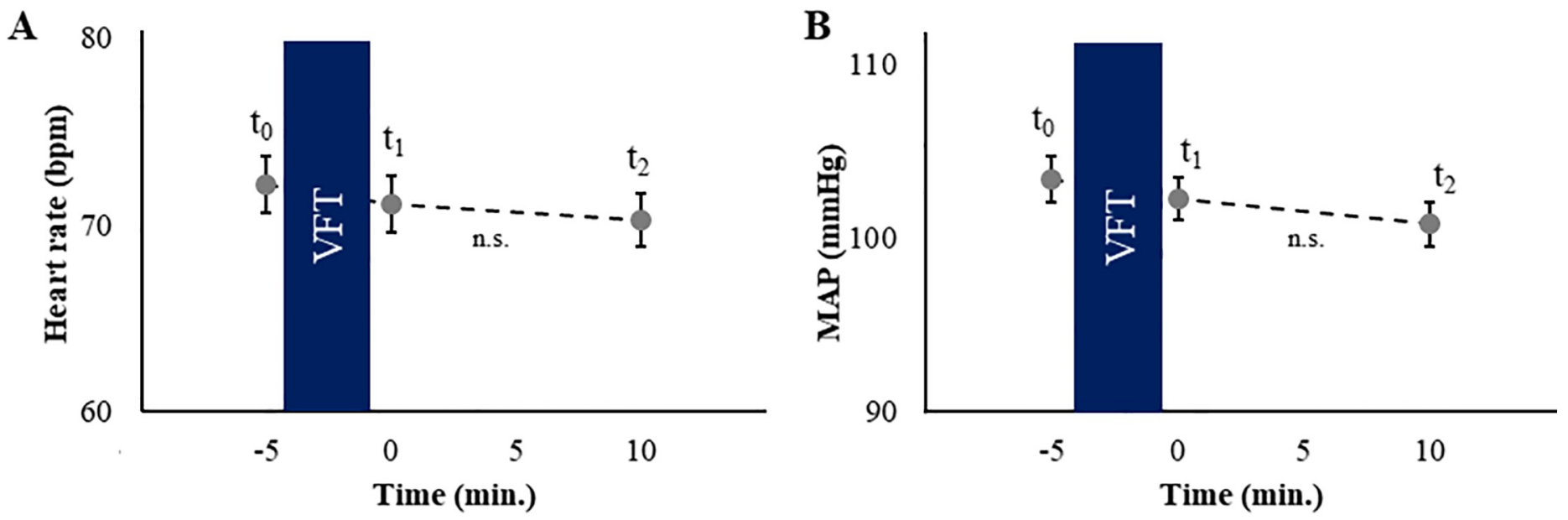

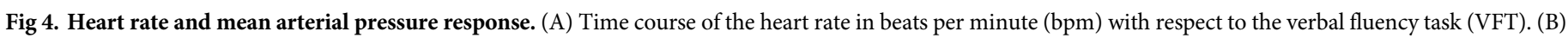
Time course of the mean arterial pressure (MAP). Standard errors are shown as error bars.

https://doi.org/10.1371/journal.pone.0227721.g004 
activity and responses to acute stressors when other stress tasks are used (e.g., [29-33,35]) are related with the stress response or with VF performance in our study, exploratory analyses were conducted. Furthermore, it was investigated whether the time of day was related with the stress response or with the VF performance, because a part of the experiment was conducted during a public event in the evening, and the rest was carried out in the morning or the afternoon.

Anthropometric variables. First, it was investigated whether the stress response in our experiment was associated with the factors age, sex, and BMI that are known to be typically related with the stress response [30-32]. However, no associations were found when using the adjusted $\alpha$-level of $\alpha_{\text {adj }}=.002$ (all $p \geq .003$ ).

Use of oral contraceptives. Next, it was investigated whether VF performance or the physiological variables differed between women who use oral contraceptives and women who do not because it has been shown previously that oral contraceptives might affect stress axes activity [35]. However, no differences were found (all $p \geq .208$ ).

Depression. Since it has been shown previously that the stress response and cognitive performance can be associated with depression (e.g., [33,52]), it was investigated whether this can be found in our study as well. Correlation analyses indicated that neither the physiological variables nor the cognitive performance were associated with depression (all $p \geq .113$ ). Only negative affect and level of effort at $t_{0}$ were related with depression (negative affect: $r_{(78)}=.45, p<.001$, effort at $\left.t_{0}: r_{(78)}=.38, p=.001\right)$. After classifying the participants into depressed and non-depressed according to the cut-off value by Stein and Luppa (2012; [36]), only a difference in negative affect was found between the groups $\left(t_{(75}\right)=-4.25, p<.001$, $\left.d=1.4, \mathrm{M}_{\text {non-depressed }}=1.3 \pm 0.32, \mathrm{M}_{\text {depressed }}=1.9 \pm 0.63\right)$. Neither the physiological variables nor the other measures differed between depressed and non-depressed participants (all $p>.014)$.

Chronic stress. Next, it was investigated whether the stress response was associated with the level of perceived life stress during the last month because it is well known that chronic stress can alter stress axis activity (e.g., $[53,54]$ ). Perceived stress at $t_{0}$ and $t_{1}$ as well as positive and negative affect were related with the PSS score (perceived stress at $t_{0}: r_{(83)}=.33, p=.002$, perceived stress at $\mathrm{t}_{1}: r_{(83)}=.34, p=.002$, positive affect: $r_{(76)}=-.31, p=.001$; negative affect: $\left.r_{(76)}=.51, p<.001\right)$. Furthermore, a marginally significant association between VFT performance and PSS scores was found $\left(r_{(83)}=.28, p=.008\right)$. None of the physiological variables were related to PSS levels (all $p \geq .105$ ). After classifying the participants into low- and highchronically stressed according to the cut-off values by Klein et al. (2016; [44]), a significant difference for positive affect $\left.\left(t_{(76}\right)=3.53, p<.001, d=0.77 ; \mathrm{M}_{\text {low }}=3.3 \pm 0.62, \mathrm{M}_{\text {high }}=2.8 \pm 0.69\right)$ and a marginal difference in perceived stress at $\mathrm{t}_{1}\left(t_{(83}\right)=-2.73, p=.008, d=0.6 ; \mathrm{M}_{\mathrm{low}}=$ $4.1 \pm 1.86, \mathrm{M}_{\text {high }}=5.2 \pm 1.86$ ) was found between the low- and the high-chronically stressed participants.

Time of day. At last, it was analyzed whether time of day was associated with task performance, baseline levels, or with the stress response. All cortisol levels were associated with time of day $\left(\mathrm{t}_{0}: r_{(83)}=-.54, p<.001, \mathrm{t}_{1}: r_{(83)}=-.50, p<.001, \mathrm{t}_{2}: r_{(83)}=-.42, p<.001\right.$, However, the percentage of the cortisol increase (between $t_{0}$ and $t_{2}$ (i.e., the HPA axis response) which was calculated as cort increase $=\left[\operatorname{cort}_{\mathrm{t} 2}-\operatorname{cort}_{\mathrm{t} 0}\right]^{*} 100 / \mathrm{cort}_{\mathrm{t} 0}$, and therefore the stress response, was not related with time of day $(p=.052)$. With a further rmANOVA, only main effects of the withinsubject factor time $\left(F_{(1.38,113.23)}=9.88, p=.001, \eta_{\mathrm{p}}{ }^{2}=.11\right)$ and the between-subjects factor 'time of day-category' $\left(F_{(2,82)}=13.74, p<.001, \eta_{\mathrm{p}}{ }^{2}=.25\right)$, but no interaction time $\mathrm{x}$ time of day-category was found $(p=.169)$. No associations were found for the other variables (neither for the physiological nor the perceived ratings nor for VF performance; all $p>.003$ ). 


\section{Discussion}

The aim of our study was to investigate whether a VFT induces an acute stress response, i.e. if it leads to an increase in the activity of the SNS and the HPA axis and to an increase in perceived stress. Furthermore, we aimed to investigate whether-if an acute stress response was found-this was associated with VF performance. We hypothesized that higher stress responses would be related with poorer performance.

As expected, an increase of cortisol levels and, therefore, an increase in HPA axis activity was found. This was not related with VF performance. Furthermore, levels of perceived stress and effort as well as tiredness were higher immediately after the VFT than before. However, changes in HPA axis activity and ratings of perceived stress and effort were not associated with cognitive performance during the task. Only tiredness immediately after the task was negatively associated with task performance. No changes in SNS activity were found at all, neither in sAA levels, nor in blood pressure, nor in heart rate.

Associations between HPA axis activity and VF performance have been reported previously. Greendale, Kritz-Silverstein, Seeman, and Barrett-Connor (2000; [55]) found that basal cortisol levels predicted VF performance four years later, i.e. higher cortisol levels were associated with worse verbal fluency performance. Fiocco, Joober, and Lupien $(2007 ;$ [56]) reported that participants with lower educational levels (which might be associated with poorer VF performance) showed higher cortisol responses to a TSST and performed worse in a VFT than participants with higher educational levels. Unfortunately, we were not able to investigate whether educational level was associated with the VF performance or with the HPA axis response in our study because of too small group sizes.

Numerous stress induction tasks have been developed so far such as the TSST [24,57] or the Montreal Imaging Stress Task (MIST; [58]) which include combinations of social-evaluative and cognitive stressors, or the socially evaluated cold-pressor test (SECPT; [59-61]) which involves a physiological and a social-evaluative stress component. The speciality in our study was that we used a purely cognitive stressor without inducing a social-evaluative component. Other cognitive stressors (e.g., mathematical $[62,63]$ or inhibition tasks such as the Stroop task; [64]) have been proposed previously and have been shown to induce subjective and physiological stress responses as well. However, to the best of our knowledge we were the first who have shown that a VFT can be a suitable alternative, especially when HPA axis and perceived stress responses are intended.

At first glance, it is astonishing that no response of the SNS could be found in our study, because usually this is a reliable, quickly activated stress indicator. Therefore, it might have been that our SNS markers were not sensitive enough to detect changes in response to the VFT and that we should have used alternatives such as blood samples of epinephrine or norepinephrine, electrodermal activity, or heart rate variability. However, if our finding could be replicated in future research, this would have interesting theoretical implications that fit well into modern stress theories. In contrast to the widespread view that there is a general stress response that is independent of the type of the stressor (so-called generality model; [2]), the integrated specificity model [25] is becoming increasingly popular. The main assumption of this model is that the stress response is specific and that it depends on the stressor characteristics, e.g. whether the stressor is threatening or challenging, emotional, social-evaluative, or cognitive. According to the integrated specificity model, different physiological reactions occur, depending on the stressor's properties. Social-evaluative stressors, for example, which elicit the emotion shame, lead to strong HPA axis responses (so-called Social-Self Preservation Theory; [65]). Cognitive stressors have been shown to elicit HPA axis responses as well [66] which can be amplified when combined with social-evaluative stressors. In contrast, 
threatening and emotional stressors have been shown to elicit strong SNS responses [2]. Therefore, our results fit well into this modern approach of stress specificity.

Overall, we suggest that a VFT can be an easy to implement alternative to other laboratory stress tasks that use pure cognitive stressors. This has the further advantage that cognitive performance can be measured at the same time as the stress induction. However, we cannot completely rule out that we created a social-evaluative component accidentally. This could have happened through the dictaphone that was placed in front of the participants or through the presence of our assistants. In future research, it should therefore be investigated whether a VFT without the presence of an experimenter and without a (visible) dictaphone leads to the same effects.

Our results have some practical implications because VFT are a standard procedure in neuropsychological assessments. An HPA axis activation after this test could affect subsequent physiological measurements as well as performance in subsequent cognitive assessments. However, this is a problem that cannot be ruled out and that is likely to occur in all cognitive assessments.

A number of additional exploratory analyses were performed to investigate whether associations can be found with anthropometric and health factors (e.g., age, sex, BMI, chronic stress, depression, and use of oral contraceptives) which are typically related with HPA axis and SNS activity or cognitive performance [29-33,35]. However, no associations between the stress response or VF performance and these variables were found. Therefore, we conclude that it is not necessary to include them as control variables in future studies when the same task is used. However, future research is needed to replicate this lack of findings.

The main limitation of our study might be that a part of it was conducted in the late evening until midnight which is not typical for laboratory settings. Due to the circadian rhythm of the HPA axis, cortisol levels are lower in the evening than at earlier times of the day $[53,67]$. This was also found in our study. However, no association between the HPA axis response (i.e., the percentual cortisol increase) and time of day was found. A significant cortisol increase was found independently of the baseline cortisol level and independently of the time of day. Furthermore, the large range in assessment times could also be seen as an advantage because it enabled us to recruit a variety of participants. Furthermore, clinical assessments in which the VFT is usually used also take place at different times of the day. Our study is subject to some further limitations that should be addressed in future research. Most importantly, other physiological variables (e.g., heart rate variability, blood samples of epinephrine and norepinephrine, and electrodermal activity) should be measured to verify that indeed no SNS activation has been induced. Furthermore, brain activity (e.g., assessed by means of electroencephalography recordings) and its association with the stress response should be investigated as an additional measure to VF performance to evaluate whether different cognitive demands (and, therefore, different neural processes) are associated with the stress response. Furthermore, longer time intervals should be used in future research to assess the time point and peak amplitude of the maximal cortisol increase as well as HPA axis recovery. Besides, other control variables which have been shown to be related to HPA axis responses or to VF performance (e.g., education, childhood traumata, general cognitive performance, physical health, or neurological diseases in which cognitive performance is impaired; e.g. [56,68,69]) should be included in future studies. Additionally, sex hormones should be assessed in future studies because the HPA axis and the hypothalamic-pituitary-gonadal axis could interact which typically leads to stronger HPA axis responses in men than in women [29,70,71]. This might have influenced our results as well, although no sex differences were found. The assessment of the participants' sex by means of questionnaires only might have not been enough. Moreover, we did not control for animal anxiety or phobia or for mental or physical problems related to food which 
might have affected VF performance in the respective categories. Therefore, either this should be assessed in future studies or other neutral categories should be used. Last, further variations of the VFT should be investigated in future research such as using a phonemic fluency task, using only emotional or neutral categories, or using more categories.

\section{Conclusions}

We conclude that a VFT is an acute stressor that induces a cortisol response without the need of further (e.g., social-evaluative) stress components. Therefore, it is a less time-consuming alternative to other stress tasks that can be used in field studies without much effort. Furthermore, our results fit well into the integrated specificity model and do not support the view of a general, unspecific stress response. However, the lack of an SNS response must be replicated in future studies.

\section{Supporting information}

S1 File.

(XLSX)

S2 File.

(XLSX)

\section{Acknowledgments}

We thank the visitors of the 'Lange Nacht der Wissenschaften 2019' for their interest in our work and for participating in this study. Furthermore, we thank Isabella Critelli, Aylin Gögsen, Emely Reyentanz, Luisa Schramm, and Theresa Walter for data collection.

\section{Author Contributions}

Conceptualization: Linda Becker, Ursula Schade.

Data curation: Linda Becker.

Formal analysis: Linda Becker.

Investigation: Linda Becker.

Methodology: Linda Becker, Ursula Schade.

Project administration: Linda Becker, Ursula Schade.

Supervision: Linda Becker, Nicolas Rohleder.

Visualization: Linda Becker.

Writing - original draft: Linda Becker.

Writing - review \& editing: Linda Becker, Nicolas Rohleder.

\section{References}

1. Fulford AJ, Harbuz MS. An introduction to the HPA axis. In: Techniques in the Behavioral and Neural Sciences: Elsevier; 2005. p. 43-65.

2. Selye $H$. Stress and the general adaptation syndrome. British medical journal 1950; 1(4667):1383. https://doi.org/10.1136/bmj.1.4667.1383 PMID: 15426759

3. Chrousos GP, Gold PW. The concepts of stress and stress system disorders: Overview of physical and behavioral homeostasis. Jama 1992; 267(9):1244-52. PMID: 1538563 
4. Stratakis CA, Chrousos GP. Neuroendocrinology and pathophysiology of the stress system. Annals of the New York Academy of Sciences 1995; 771(1):1-18.

5. Ulrich-Lai YM, Herman JP. Neural regulation of endocrine and autonomic stress responses. Nature reviews neuroscience 2009; 10(6):397. https://doi.org/10.1038/nrn2647 PMID: 19469025

6. Sapolsky RM. Why stress is bad for your brain. Science 1996; 273(5276):749-50. https://doi.org/10. 1126/science.273.5276.749 PMID: 8701325

7. McEwen BS, Sapolsky RM. Stress and cognitive function. Current opinion in neurobiology 1995; 5 (2):205-16. https://doi.org/10.1016/0959-4388(95)80028-x PMID: 7620309

8. Lupien SJ, Maheu F, Tu M, Fiocco A, Schramek TE. The effects of stress and stress hormones on human cognition: Implications for the field of brain and cognition. Brain and cognition 2007; 65(3):20937. https://doi.org/10.1016/j.bandc.2007.02.007 PMID: 17466428

9. Kirschbaum C, Wolf OT, May M, Wippich W, Hellhammer DH. Stress-and treatment-induced elevations of cortisol levels associated with impaired declarative memory in healthy adults. Life Sci 1996; 58 (17):1475-83. https://doi.org/10.1016/0024-3205(96)00118-x PMID: 8622574

10. Lupien SJ, Gaudreau S, Tchiteya BM, Maheu F, Sharma S, Nair NPV, et al. Stress-induced declarative memory impairment in healthy elderly subjects: relationship to cortisol reactivity. The Journal of Clinical Endocrinology \& Metabolism 1997; 82(7):2070-5.

11. Wolf OT. Stress and memory in humans: Twelve years of progress? Brain research 2009; 1293:14254. https://doi.org/10.1016/j.brainres.2009.04.013 PMID: 19376098

12. Oei NYL, Everaerd WT, Elzinga BM, van Well S, Bermond B. Psychosocial stress impairs working memory at high loads: an association with cortisol levels and memory retrieval. Stress 2006; 9(3):13341. https://doi.org/10.1080/10253890600965773 PMID: 17035163

13. Schoofs $D$, Preuß D, Wolf OT. Psychosocial stress induces working memory impairments in an $n$-back paradigm. Psychoneuroendocrinology 2008; 33(5):643-53. https://doi.org/10.1016/j.psyneuen.2008. 02.004 PMID: 18359168

14. Becker L, Rohleder N. Time course of the physiological stress response to an acute stressor and its associations with the primacy and recency effect of the serial position curve. PLoS ONE 2019; 14(5): e0213883. https://doi.org/10.1371/journal.pone.0213883 PMID: 31100063

15. Vedhara K, Hyde J, Gilchrist ID, Tytherleigh M, Plummer S. Acute stress, memory, attention and cortisol. Psychoneuroendocrinology 2000; 25(6):535-49. https://doi.org/10.1016/s0306-4530(00)00008-1 PMID: 10840167

16. Shields GS, Sazma MA, McCullough AM, Yonelinas AP. The effects of acute stress on episodic memory: a meta-analysis and integrative review. Psychological bulletin 2017; 143(6):636. https://doi.org/10. 1037/bul0000100 PMID: 28368148

17. Shields GS, Bonner JC, Moons WG. Does cortisol influence core executive functions? A meta-analysis of acute cortisol administration effects on working memory, inhibition, and set-shifting. Psychoneuroendocrinology 2015; 58:91-103. https://doi.org/10.1016/j.psyneuen.2015.04.017 PMID: 25973565

18. Het S, Ramlow G, Wolf OT. A meta-analytic review of the effects of acute cortisol administration on human memory. Psychoneuroendocrinology 2005; 30(8):771-84. https://doi.org/10.1016/j.psyneuen. 2005.03.005 PMID: 15919583

19. Schwabe L, Wolf OT. Stress and multiple memory systems: From 'thinking'to 'doing'. Trends in cognitive sciences 2013; 17(2):60-8. https://doi.org/10.1016/j.tics.2012.12.001 PMID: 23290054

20. Baddeley A. Exploring the central executive. The Quarterly Journal of Experimental Psychology: Section A 1996; 49(1):5-28.

21. Ruff RM, Light RH, Parker SB, Levin HS. The psychological construct of word fluency. Brain and language 1997; 57(3):394-405. https://doi.org/10.1006/brln.1997.1755 PMID: 9126423

22. Henry JD, Crawford JR. A meta-analytic review of verbal fluency performance following focal cortical lesions. Neuropsychology 2004; 18(2):284. https://doi.org/10.1037/0894-4105.18.2.284 PMID: 15099151

23. Buchanan TW, Laures-Gore JS, Duff MC. Acute stress reduces speech fluency. Biol Psychol 2014; 97:60-6. https://doi.org/10.1016/j.biopsycho.2014.02.005 PMID: 24555989

24. Kirschbaum C, Pirke K-M, Hellhammer DH. The 'Trier Social Stress Test'-a tool for investigating psychobiological stress responses in a laboratory setting. Neuropsychobiology 1993; 28(1-2):76-81. https://doi.org/10.1159/000119004 PMID: 8255414

25. Kemeny ME. The psychobiology of stress. Current directions in psychological science 2003; 12(4):1249.

26. Lazarus RS. Theory-based stress measurement. Psychological inquiry 1990; 1(1):3-13. 
27. Campbell J, Ehlert U. Acute psychosocial stress: does the emotional stress response correspond with physiological responses? Psychoneuroendocrinology 2012; 37(8):1111-34. https://doi.org/10.1016/j. psyneuen.2011.12.010 PMID: 22260938

28. Nater UM, Rohleder N, Gaab J, Berger S, Jud A, Kirschbaum C, et al. Human salivary alpha-amylase reactivity in a psychosocial stress paradigm. Int J Psychophysiol 2005; 55(3):333-42. https://doi.org/10 1016/j.jpsycho.2004.09.009 PMID: 15708646.

29. Stephens MAC, Mahon PB, McCaul ME, Wand GS. Hypothalamic-pituitary-adrenal axis response to acute psychosocial stress: Effects of biological sex and circulating sex hormones. Psychoneuroendocrinology 2016; 66:47-55. https://doi.org/10.1016/j.psyneuen.2015.12.021 PMID: 26773400

30. Kudielka BM, Kirschbaum C. Sex differences in HPA axis responses to stress: A review. Biol Psychol 2005; 69(1):113-32. https://doi.org/10.1016/j.biopsycho.2004.11.009 PMID: 15740829

31. McInnis CM, Thoma MV, Gianferante D, Hanlin L, Chen X, Breines JG, et al. Measures of adiposity predict interleukin-6 responses to repeated psychosocial stress. Brain Behav Immun 2014; 42:33-40. https://doi.org/10.1016/j.bbi.2014.07.018 PMID: 25107874.

32. Jones A, McMillan MR, Jones RW, Kowalik GT, Steeden JA, Deanfield JE, et al. Adiposity is associated with blunted cardiovascular, neuroendocrine and cognitive responses to acute mental stress. PLoS ONE 2012; 7(6):e39143. https://doi.org/10.1371/journal.pone.0039143 PMID: 22745709

33. Gold PW. The organization of the stress system and its dysregulation in depressive illness. Molecular psychiatry 2015; 20(1):32-47. https://doi.org/10.1038/mp.2014.163 PMID: 25486982

34. Stoney CM, Matthews KA, Mcdonald RH, Johnson CA. Sex differences in lipid, lipoprotein, cardiovascular, and neuroendocrine responses to acute stress. Psychophysiology 1988; 25(6):645-56. https:// doi.org/10.1111/j.1469-8986.1988.tb01902.x PMID: 3241852

35. Kirschbaum C, Kudielka BM, Gaab J, Schommer NC, Hellhammer DH. Impact of gender, menstrual cycle phase, and oral contraceptives on the activity of the hypothalamus-pituitary-adrenal axis. Psychosom Med 1999; 61(2):154-62. https://doi.org/10.1097/00006842-199903000-00006 PMID: 10204967

36. Stein J, Luppa M. Allgemeine Depressionsskala (ADS). Psychiat Prax 2012; 39(06):302-4. https://doi. org/10.1055/s-0032-1326702DE

37. Aschenbrenner S, Tucha O, Lange K. Regensburger Wortflüssigkeitstest (2000). Lisse: Swets und Zeitlinger Verlag.

38. Bosch JA, Geus EJC de, Veerman ECI, Hoogstraten J, Amerongen AVN. Innate secretory immunity in response to laboratory stressors that evoke distinct patterns of cardiac autonomic activity. Psychosom Med 2003; 65(2):245-58. https://doi.org/10.1097/01.psy.0000058376.50240.2d PMID: 12651992

39. Rohleder N, Nater UM. Determinants of salivary alpha-amylase in humans and methodological considerations. Psychoneuroendocrinology 2009; 34(4):469-85. https://doi.org/10.1016/j.psyneuen.2008.12. 004 PMID: 19155141.

40. Meaney E, Alva F, Moguel R, Meaney A, ALVA J, WEBEL R. Formula and nomogram for the sphygmomanometric calculation of the mean arterial pressure. Heart 2000; 84(1):64. https://doi.org/10.1136/ heart.84.1.64 PMID: 10862592

41. Radloff LS. The CES-D scale: A self-report depression scale for research in the general population. Applied psychological measurement 1977; 1(3):385-401.

42. Hautzinger M, Bailer M, Hofmeister D, Keller F. ADS: Allgemeine Depressionsskala: Testhandbuch ( 2te Ausgabe): Göttingen: Hogrefe; 2012.

43. Cohen S, Kamarck T, Mermelstein R. A global measure of perceived stress. Journal of health and social behavior 1983:385-96. PMID: 6668417

44. Klein EM, Brähler E, Dreier M, Reinecke L, Müller KW, Schmutzer G, et al. The German version of the Perceived Stress Scale-psychometric characteristics in a representative German community sample. BMC psychiatry 2016; 16(1):159.

45. Krohne HW, Egloff B, Kohlmann C-W, Tausch A. Untersuchungen mit einer deutschen Version der"Positive and Negative Affect Schedule"(PANAS). Diagnostica 1996; 42:139-56.

46. Watson D, Clark LA, Tellegen A. Development and validation of brief measures of positive and negative affect: the PANAS scales. Journal of personality and social psychology 1988; 54(6):1063. https://doi. org/10.1037//0022-3514.54.6.1063 PMID: 3397865

47. Thompson ER. Development and validation of an internationally reliable short-form of the positive and negative affect schedule (PANAS). Journal of cross-cultural psychology 2007; 38(2):227-42.

48. Sinclair J, Taylor PJ, Hobbs SJ. Alpha level adjustments for multiple dependent variable analyses and their applicability-a review. Int J Sports Sci Eng 2013; 7(1):17-20.

49. Mauchly JW. Significance test for sphericity of a normal n-variate distribution. The Annals of Mathematical Statistics 1940; 11(2):204-9. 
50. Greenhouse SW, Geisser S. On methods in the analysis of profile data. Psychometrika 1959; 24(2):95112.

51. Morris SB. Estimating effect sizes from pretest-posttest-control group designs. Organizational research methods 2008; 11(2):364-86.

52. Charmandari E, Tsigos C, Chrousos G. Endocrinology of the stress response. Annu. Rev. Physiol. 2005; 67:259-84. https://doi.org/10.1146/annurev.physiol.67.040403.120816 PMID: 15709959

53. Miller GE, Chen E, Zhou ES. If it goes up, must it come down? Chronic stress and the hypothalamicpituitary-adrenocortical axis in humans: American Psychological Association; 2007.

54. Juster R-P, McEwen BS, Lupien SJ. Allostatic load biomarkers of chronic stress and impact on health and cognition. Neuroscience \& Biobehavioral Reviews 2010; 35(1):2-16.

55. Greendale GA, Kritz-Silverstein D, Seeman T, Barrett-Connor E. Higher basal cortisol predicts verbal memory loss in postmenopausal women: Rancho Bernardo Study. Journal of the American Geriatrics Society 2000; 48(12):1655-8. https://doi.org/10.1111/j.1532-5415.2000.tb03878.x PMID: 11129757

56. Fiocco AJ, Joober R, Lupien SJ. Education modulates cortisol reactivity to the Trier Social Stress Test in middle-aged adults. Psychoneuroendocrinology 2007; 32(8-10):1158-63. https://doi.org/10.1016/j. psyneuen.2007.08.008 PMID: 17920776

57. Dawans B von, Kirschbaum C, Heinrichs M. The Trier Social Stress Test for Groups (TSST-G): A new research tool for controlled simultaneous social stress exposure in a group format. Psychoneuroendocrinology 2011; 36(4):514-22. https://doi.org/10.1016/j.psyneuen.2010.08.004 PMID: 20843608

58. Dedovic K, Renwick R, Mahani NK, Engert V, Lupien SJ, Pruessner JC. The Montreal Imaging Stress Task: using functional imaging to investigate the effects of perceiving and processing psychosocial stress in the human brain. Journal of Psychiatry and Neuroscience 2005; 30(5):319. PMID: 16151536

59. Schwabe L, Haddad L, Schachinger H. HPA axis activation by a socially evaluated cold-pressor test Psychoneuroendocrinology 2008; 33(6):890-5. https://doi.org/10.1016/j.psyneuen.2008.03.001 PMID: 18403130

60. Minkley N, Schröder TP, Wolf OT, Kirchner WH. The socially evaluated cold-pressor test (SECPT) for groups: Effects of repeated administration of a combined physiological and psychological stressor. Psychoneuroendocrinology 2014; 45:119-27. https://doi.org/10.1016/j.psyneuen.2014.03.022 PMID: 24845183

61. Becker L, Schade U, Rohleder N. Evaluation of the socially evaluated cold-pressor group test (SECPTG) in the general population. PeerJ 2019; 7:e7521. https://doi.org/10.7717/peerj.7521 PMID: 31423367

62. McHugh RK, Behar E, Gutner CA, Geem D, Otto MW. Cortisol, stress, and attentional bias toward threat. Anxiety, Stress, \& Coping 2010; 23(5):529-45.

63. Mattarella-Micke A, Mateo J, Kozak MN, Foster K, Beilock SL. Choke or thrive? The relation between salivary cortisol and math performance depends on individual differences in working memory and mathanxiety. Emotion 2011; 11(4):1000. https://doi.org/10.1037/a0023224 PMID: 21707166

64. Skoluda N, Strahler J, Schlotz W, Niederberger L, Marques S, Fischer S, et al. Intra-individual psychological and physiological responses to acute laboratory stressors of different intensity. Psychoneuroendocrinology 2015; 51:227-36. https://doi.org/10.1016/j.psyneuen.2014.10.002 PMID: 25462896

65. Gruenewald TL, Kemeny ME, Aziz N, Fahey JL. Acute threat to the social self: Shame, social selfesteem, and cortisol activity. Psychosom Med 2004; 66(6):915-24. https://doi.org/10.1097/01.psy 0000143639.61693. ef PMID: 15564358

66. Dickerson SS, Kemeny ME. Acute stressors and cortisol responses: a theoretical integration and synthesis of laboratory research. Psychological bulletin 2004; 130(3):355. https://doi.org/10.1037/00332909.130.3.355 PMID: 15122924

67. Nater UM, Rohleder N, Schlotz W, Ehlert U, Kirschbaum C. Determinants of the diurnal course of salivary alpha-amylase. Psychoneuroendocrinology 2007; 32(4):392-401. https://doi.org/10.1016/j. psyneuen.2007.02.007 PMID: 17418498

68. Gillespie CF, Phifer J, Bradley B, Ressler KJ. Risk and resilience: genetic and environmental influences on development of the stress response. Depression and anxiety 2009; 26(11):984-92. https://doi.org/ 10.1002/da.20605 PMID: 19750552

69. Bergman I, Almkvist O. Neuropsychological test norms controlled for physical health: Does it matter? Scandinavian journal of psychology 2015; 56(2):140-50. https://doi.org/10.1111/sjop.12170 PMID: 25356656

70. Da Silva JAP. Sex hormones and glucocorticoids: interactions with the immune system. Annals of the New York Academy of Sciences 1999; 876(1):102-18.

71. Oyola MG, Handa RJ. Hypothalamic-pituitary-adrenal and hypothalamic-pituitary-gonadal axes: sex differences in regulation of stress responsivity. Stress 2017; 20(5):476-94. https://doi.org/10.1080/ 10253890.2017.1369523 PMID: 28859530 